EESTI NSV TEADUSTE AKADEEMIA TOIMETISED. XIII KÖIDE FOUSIKA-MATEMAATIKA- JA TEHNIKATEADUSTE SEERIA. 1964, NR. 3

ИЗВЕСТИЯ АКАДЕМИН НАУК ЭСТОНСКОН ССР. ТОМ ХІІІ СЕРИЯ ФИЗИКО-МАТЕМАТИЧЕСКИХ И ТЕХНИЧЕСКИХ НАУК. 1964, № 3

\title{
ЕМКОСТНЫЙ ДАТЧИК НЕПРЕРЫВНОГО ДЕЙТВИЯ С ВРАЩАЮЩИМИСЯ МНОГОДИСКОВЫМИ ВАЛИКАМИ
}

\author{
3. КЮННАП, \\ кандидат технических наук
}

При регулировании технологического процесса энергоклинкерной установки для изготовления портланд-цемента из сланцевой золы возник вопрос о дозировке сыпучих исходных материалов, от точности которой зависит качество выпускаемой продукции. В этой установке отходы тепла найдут энергетическое использование.

Добываемый из открытых карьеров сланец имеет значительное колебание содержания минеральной части. В цементе количество кальция в виде СаО, не влияя существенным образом на его качество, может колебаться в пределах $\pm 1 \div 3,5 \%$ от номинального, равного $59 \div 64 \%$ (в среднем $62 \%$ ). Такие требования предъявляются и к регулятору состава шихты, который должен поддерживать в шихте такое количество $\mathrm{CaCO}_{3}$, чтобы в клинкере, после разложения шихты в топке, $\mathrm{CaO}$ осталось в пределах указанного количества.

В настоящее время нанбольше распространены два вида анализа качества цемента: 1) определение содержания свободной извести в клинкере при помощи петрографического анализа в цеховых и заводских лабораториях и 2) определение веса клинкера. Первый способ очень длительный, а второй неточный, так как хотя между весом литра клинкера и содержанием свободной извести в клинкере существует зависимость, но объемный вес клинкера может изменяться в большом диапазоне и не содержать свободной извести. Однако на заводах периодически производится определение веса просеянного клинкера для установления настроечных параметров регуляторов и для получения некоторой качественной оценки работы печи с точки зрения ровности ведения процесса. Величину отклонения веса литра клинкера характеризуют изменения в режиме обжига, независимо от среднего веса литра клинкера.

В западных государствах широко применяется способ сухого производства цемента. Полной автоматизации производства, как и многих других непрерывных технологических прощессов, еще нет. Автоматизированы лишь, отдельные узлы, а ряд важных операций управляется еще вручную. В ФРГ разработана схема регулирования качества клинкера при помощи рентгенофлуоресенцанализа. Для получения достоверных данных, хорошо совпадающих с данными химического анализа, время вышеуказанного анализа составляло $8 \div 16$ мин.

При анализе состава цемента вместо рентгеновских лучей используются лучи радиоактивных изотопов. На некоторых заводах США для этого применяется изотоп $\mathrm{Am}^{241}$. Погрешность этих методов составляет $1 \div 5 \%$ при времени измерения порядка нескольких секунд. Однако все эти установки измерения весьма громоздкие.

Таким образом, технологические процессы изготовления высококачественного цемента практически не регулируются.

Качество клинкера считают удовлетворительным, если прощесс обжига пронсходит при соответствующей температуре. Приведенные методы определения качества клинкера являются только контрольными и применяются лишь периодически. Применение этих методов в системах управления связано с большими трудностями из-за сложности установок и длительности получения результатов измерения. Это касается и опытов по применению оптического спектрального анализа.

В энергоклинкерной установке используется сухой способ изготовления материала для обжига. Нсходя из условий прохождения технологического процесса, метод определения веса литра клинкера в данном случае трудно применять в качестве регулятора 
состава шихты. Кроме того, как уже указывалось, в случае обжига клинкера доо отсутствия свободной СаO в нем, вес литра клинкера не определяет его качества.

В установке, строящейся в ТЭЩ Кохтла-Ярве, исходный материал подается в топку для обжига в виде смеси пылевидного сланца и известняка, при этом кероген сланцевых частиц сгорает, а минеральные части сланца и известняка образуют химическое соединение клинкера. Если поддерживать температурный режим в топке в нужных пределах $\left(2000 \pm 25^{\circ} \mathrm{C}\right)$, то качество соединения $\mathrm{SiO}_{2} \mathrm{C} \mathrm{CaO}$ зависит главным образом от процентного содержания $\mathrm{CaCO}_{3}$ в смеси сланца и известняка.

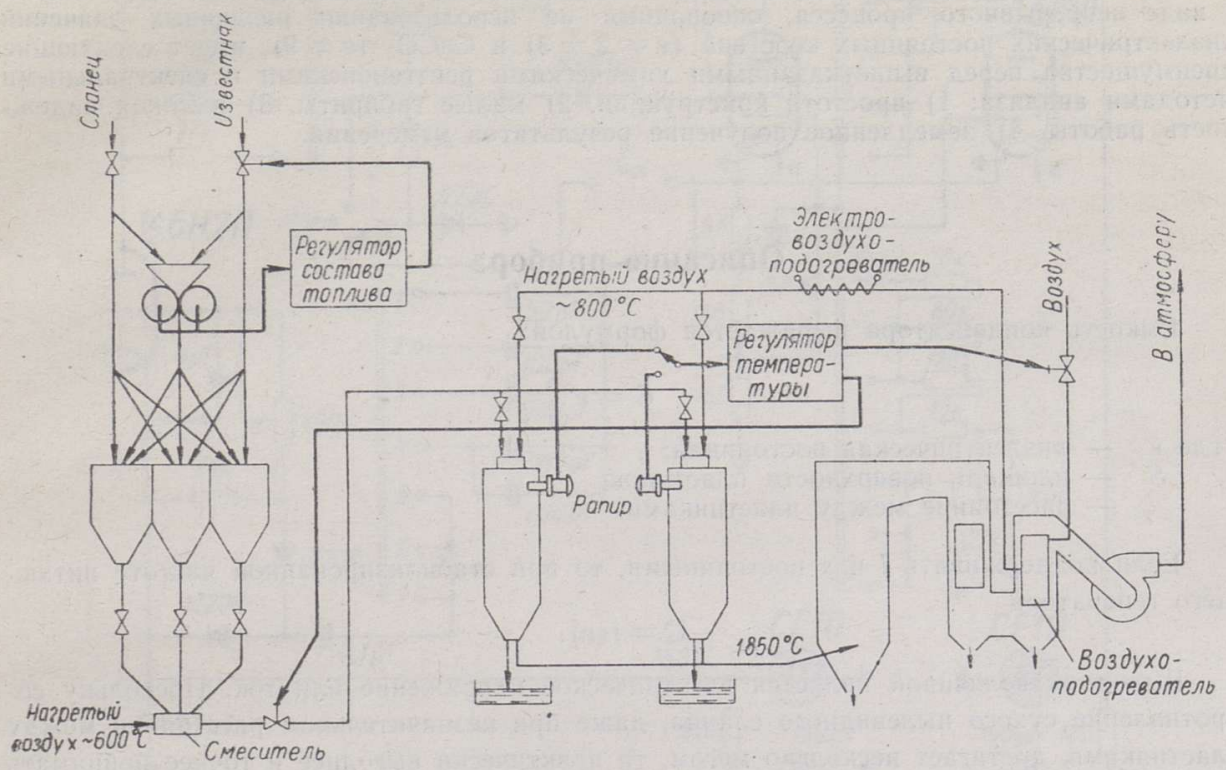

Pнс. 1.

Упрощенная схема технологического процесса опытной промышленной установки для получения клинкера приведена на рис. 1. Топливо - сланец III сорта - подается ленточным транспортером в дробилку и оттуда в молотковую мельнищу. Транспорт сланцевой и известняковой пыли в циклоны и их сушка производится дымовыми газами..Сланец и известняк подаются в промежуточные бункера, а оттуда через дозатор в щиклонную топку. Клинкер, выходящий из топки, подвергается быстрому охлаждению водой. Часть дымовых газов используется также для нагрева воздуха, остальная часть тепла для энергетической цели.

Количество свободной окиси кальция в расплавленном клинкере, велнчина которого определяет качество клинкера, зависит от общего содержания СаO в нем, температурного уровня сгорания и режима охлаждения расплава. Количество свободной окиси каль-

Таблища 1 ция в охлажденном клинкере тем меньше, чем меньше в нем обшее содержание $\mathrm{CaO}$ и чем больше температура расплава превышает температуру начала кристаллизации его. Номинальной температурой процесса горения в данной установке принята $2000^{\circ}$, т. е. на $150^{\circ}$ выше уровня температуры кристаллизации трехкальциевого силиката $\left(1850^{\circ}\right)$. В данной установке применяют метод быстрого охлаждения расплавленного клинкера в воде.

В исходных материалах (сланец, известняк), кроме других компонентов $\left(\mathrm{Al}_{2} \mathrm{O}_{3}, \mathrm{Fe}_{2} \mathrm{O}_{3}\right.$ няк), кроме других компонентов $\left(\mathrm{Al}_{2} \mathrm{O}_{3}, \mathrm{Fe}_{2} \mathrm{O}_{3}\right.$

$\mathrm{SiO}_{2}$

$\mathrm{Al}_{2} \mathrm{O}_{3}$

$\mathrm{Fe}_{2} \mathrm{O}_{3}$

$\mathrm{CaO}$

$\mathrm{MgO}$
Вийвиконна (5 сквауин) $\varangle$ सू कू एक हुम हुँ

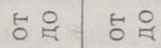

$$
5 *
$$
ного карьера оно, как и другие компоненты, кроме $\mathrm{CaCO}_{3}$, почти постоянно, а по местонахождениям карьеров изменяется в пределах $2 \div 5 \%$ (табл. 1). 
Таким образом, если стабилизировать в шихте количество $\mathrm{CaCO}_{3}$ в допустимых пределах $(\mathrm{CaO}$ в клинкере $59 \div 65 \%)$, поддерживать температуру горения в топке в пределах $2000 \pm 25^{\circ} \mathrm{C}$ и провести быстрое охлаждение клинкерного расплава (это предусмотрено по проекту), то заданное качество клинкера должно быть обеспечено.

По содержанию $\mathrm{CaCO}_{3}$ состав сланца не постоянная и зависит главным образом от точности работы обогатительного узла топливогіриготовительного цеха. Для обеспечения номинального содержания $\mathrm{CaCO}_{3}$ в шихте необходимо осуществлять его постоянный контроль.

Предлагаемый способ определения относительного количества $\mathrm{CaCO}_{3}$ в шихте в виде непрерывного процесса, основанный на использованни различных значений диэлектрических постоянных керогена $(\varepsilon=2 \div 3)$ и $\mathrm{CaCO}_{3}(\boldsymbol{\varepsilon} \approx 9)$, нмеет следуюшис преимущества перед вышеуказанными хнмическими рентгеновскими и спектральными методами анализа: 1) простота конструкции, 2) малые габариты, 3) высокая надежность работы, 4) немедленное получение результатов измерения.

\section{Описание прибора}

Емкость конденсатора выражается формулой:

$$
C=\varepsilon \frac{S}{l},
$$

где $\varepsilon$ - диэлектрическая постоянная;

$S$ - плошадь поверхности пластинок;

$l$ - расстояние между пластинками.

Если поддерживать $l$ и $s$ постоянными, то при стабнлизированной частоте питающего генератора

$$
C=f(\varepsilon)
$$

Выходной величиной является электрнческое напряжение или ток. Поскольку сопротивление сухого пылевидного сланца, даже при незначительном расстоянии между пластинками, достигает несколько мегом, то практически выгоднее и точнее принимать в качестве выходной величиіы напряжение.

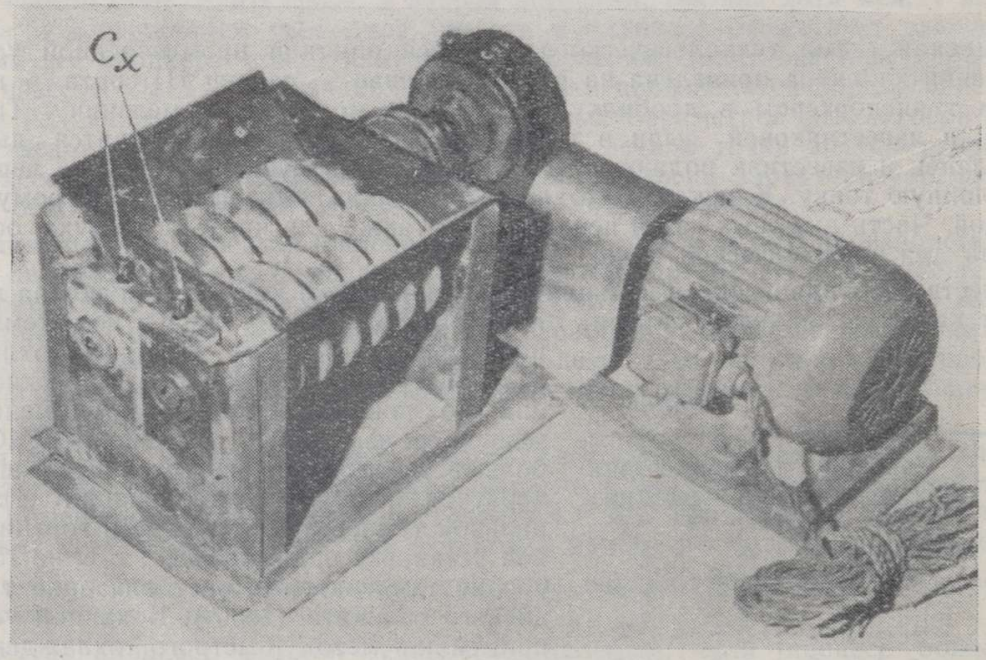

Рис. 2.

На рис. 2 показана фотография механической части прибора. Он состоит из измерительных вращающихся пластинок, диаметром 11,5 cм и рабочей поверхностью $190 \mathrm{~cm}^{2}$, редуктора $(i=40)$ и электромотора, мощностью 0,6 квт. На рис. 3 приведена схема его электронной части. Предусмотрено использовать два варианта- - прямое измере- 


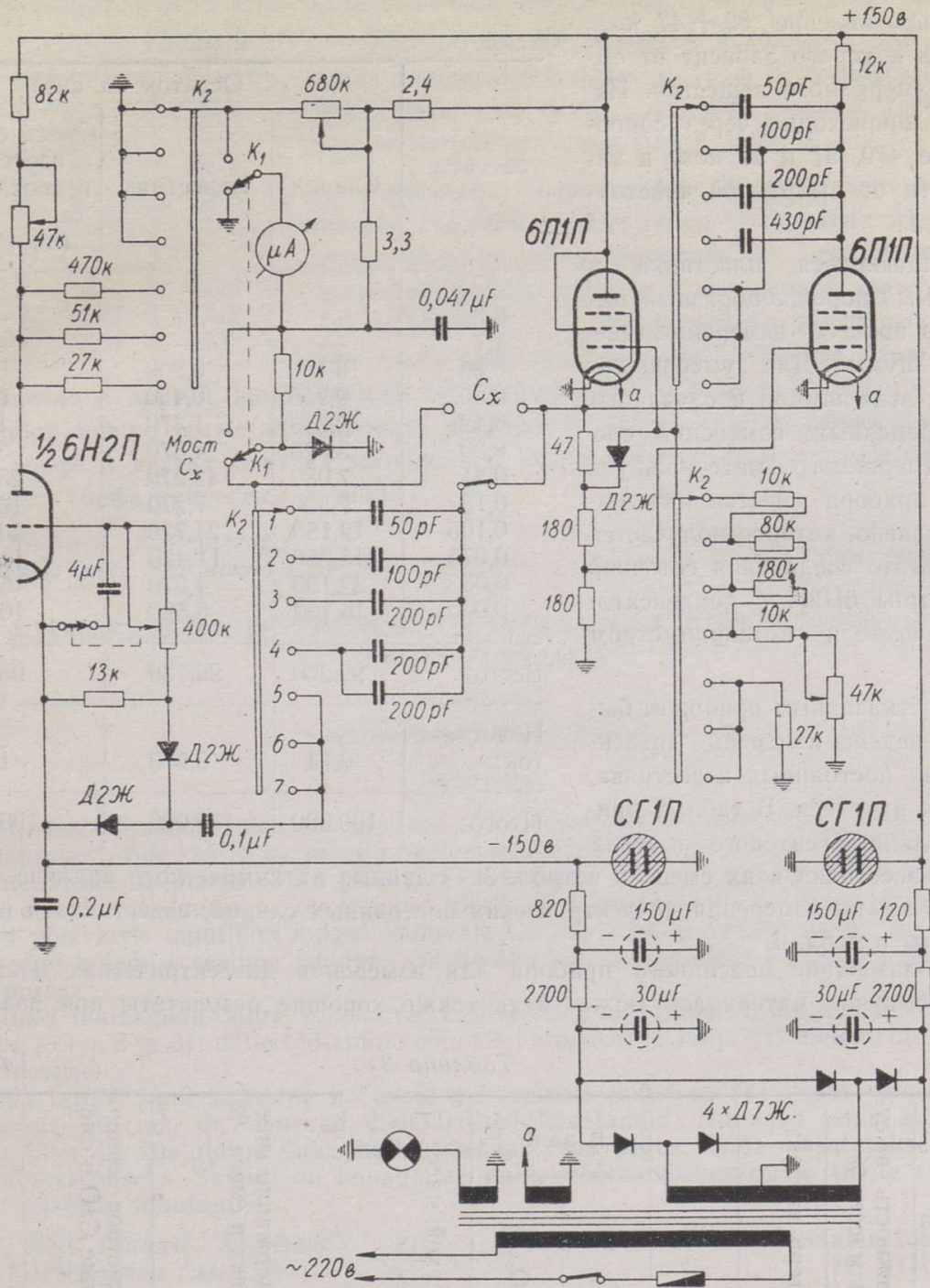

Рис. 3

ние и измерение по мостовой схеме. Частоту мультивибратора можно выбирать 30 , 60,120 и 250 кгц. Результаты измерения, полученные при частоте мультивибратора $250 \mathrm{\kappa} и$, приведены ниже. Выходное напряжение взято от нагрузочного сопротивления катода. При прямом измерении включатель $\mathrm{K}_{\mathrm{I}}$ находится в положении $\mathrm{C}_{\mathrm{x}}$, а включатель $K_{2}$, в зависимости от выбранной области измерения, в положении $1,2,3$ или 4 . Измеренный конденсатор $\mathrm{C}_{\mathrm{x}}$ (нли эталон 50, 100, 200 или 400 пф) заряжается мультивнбратором во время импульса через диод и разряжается во время отсутствия импульса через сопротивление 10 ком и амперметр 100 мка. Между током и емкостью конленсатора имеется линейная зависимость. При измерении по мостовой схеме в качестве генератора переменного тока используется мультивибратор. Включатель $\mathrm{K}_{1}$ находится в положении «мост» и включатель $\mathrm{K}_{2}-$ в положении 5, 6 или 7. Переменный ток проходит конденсаторы $\mathrm{C}_{\mathrm{x}}$ и 0,1 лкф и выпрямляется двумя диодами. Отрицательное постоянное напряжение, которое возникает на сопротивлении 13 ком и зависит от величины $\mathrm{C}_{\mathrm{x}}$, управляет лампой $6 \mathrm{H} 2$ П, нзменяя ее внутреннее сопротивление. Таким об разом, лампа 6 Н2П является одним плечом мостовой схемы, ее вторым плечом слу- 
жит сопротивление $82+47$ ком, Таблича 2 величина которого зависит от емкости измеряемого вещества. Измерение пронсходит через сопротивление 470, 51 и 27 ком, в зависимости от выбранной чувствительности.

Вращающиеся пластннки и измеряемый поропкообпазный материал в процессе измерения генерируют шумы, Для уменьшения влияния этих шумов и случайных кратковременных изменений состава нзмеряемого материала на выходе прибора имеется интегрирующее звено, которое получается в результате соединения сеточной цепи лампы 6Н2П с конденсатором 4 мкф и потенциометром 400 ком.

Вышеуказанным прибором были произведены измерения диэ.лектрических постоянных известняка, сланца и их смеси. В табл. 2 приведены данные ситового анализа

\begin{tabular}{|c|c|c|c|}
\hline \multirow[b]{2}{*}{ № сита } & \multicolumn{3}{|c|}{ Остаток на сите } \\
\hline & Сланец & Известняк & $\begin{array}{c}\text { Смесь сланца } \\
\text { известняка } \\
\text { в соотношении } \\
1: 1 \\
\text { (по объему) }\end{array}$ \\
\hline $\begin{array}{l}3,3 \\
1,7 \\
0,85 \\
0,60 \\
0,42 \\
0,30 \\
0,21 \\
0,15 \\
0,105 \\
0,075 \\
0,053 \\
0,000\end{array}$ & $\begin{array}{r}- \\
- \\
0,100 \\
0,750 \\
2,780 \\
5,320 \\
7,080 \\
7,530 \\
12,150 \\
15,350 \\
32,100 \\
16,100\end{array}$ & $\begin{array}{r}- \\
- \\
0,200 \\
0,450 \\
1,370 \\
4,370 \\
42,270 \\
7,270 \\
24,720 \\
11,420 \\
4,070 \\
3,590\end{array}$ & $\begin{array}{l}- \\
\overline{0} \\
0,200 \\
0,700 \\
1,800 \\
3,400 \\
25,020 \\
10,200 \\
20,600 \\
11,250 \\
15,200 \\
10,600\end{array}$ \\
\hline Всего: & 99,260 & 99,730 & 98,970 \\
\hline $\begin{array}{l}\text { Недоста- } \\
\text { ток: }\end{array}$ & 0,74 & 0,270 & 1,030 \\
\hline Итого: & 100,000 & 100,000 & 100,000 \\
\hline
\end{tabular}
сланца известняка и их смеси и в табл. 3 - данные их химического анализа.

Результаты измерения диэлектрических постоянных сланца, известняка и их смеси приведены в табл. 4

Использование описанного прибора для измерения диэлектрических постоянных разных сыпучих материалов может дать также хорошие результаты при различении

Таблица 3

Таблица 4

\begin{tabular}{|c|c|c|c|c|c|c|}
\hline \multirow[b]{2}{*}{ Материал } & \multirow{2}{*}{ 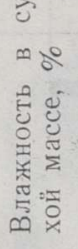 } & \multirow{2}{*}{ 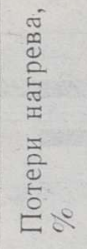 } & \multirow[b]{2}{*}{ 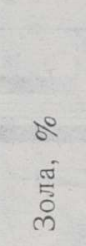 } & \multicolumn{2}{|c|}{ В золе } & \multirow{2}{*}{ 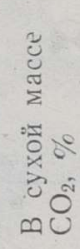 } \\
\hline & & & & $\underbrace{2}_{0}$ & $\begin{array}{l}20 \\
0 \\
\sum^{0}\end{array}$ & \\
\hline $\begin{array}{l}\text { Извест- } \\
\text { няк } \\
\text { Сланец }\end{array}$ & $\begin{array}{l}0,15 \\
0,90\end{array}$ & $\begin{array}{l}41.20 \\
55,35\end{array}$ & $\begin{array}{l}58,80 \\
44,65\end{array}$ & $\begin{array}{l}47,34 \\
18,15\end{array}$ & $\begin{array}{l}3,6 \\
3,4\end{array}$ & $\begin{array}{l}40,86 \\
18,53\end{array}$ \\
\hline
\end{tabular}

\begin{tabular}{|c|c|c|}
\hline 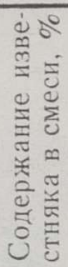 & 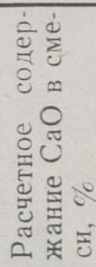 & 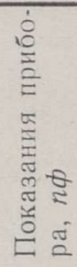 \\
\hline $\begin{array}{r}0 \\
20 \\
40 \\
60 \\
80 \\
100\end{array}$ & $\begin{array}{l}18,53 \\
23,00 \\
27,47 \\
31,93 \\
36,40 \\
40,86\end{array}$ & $\begin{array}{l}260 \\
290 \\
320 \\
340 \\
360 \\
380\end{array}$ \\
\hline
\end{tabular}

таблица .5

Таблица 6

Химический состав, \%

\begin{tabular}{l|c|c|c|c|c|c|c|c}
\hline & $\mathrm{SiO}_{2}$ & $\mathrm{Al}_{2} \mathrm{O}_{3}$ & $\mathrm{Fe}_{2} \mathrm{O}_{3}$ & $\mathrm{~K}_{2} \mathrm{O}$ & $\mathrm{MgO}$ & $\mathrm{CaO}$ & $\mathrm{SO}_{3}$ & $\mathrm{CO}_{2}$ \\
\hline $\begin{array}{l}\text { Зола A-5 } \\
\text { Песок }\end{array}$ & 25,4 & 5,9 & 6,9 & 1,9 & 4,1 & 50,8 & 2,0 & 1,7 \\
\hline
\end{tabular}

\begin{tabular}{r|c}
\hline $\begin{array}{c}\text { Содержание } \\
\text { золы } \\
\text { в смеси, \% }\end{array}$ & $\begin{array}{c}\text { Показания } \\
\text { прибора, nф }\end{array}$ \\
\hline 0 & \\
25 & 10 \\
50 & 60 \\
75 & 120 \\
100 & 190 \\
& 260
\end{tabular}


песка от сланцевой золы или ири определении относительного количества песка в золе.

таблица 7 Эти материалы являются исходными для изготов-

\begin{tabular}{|c|c|c|}
\hline $\begin{array}{l}\vec{J} \\
0 \\
0 \\
\text { E } \\
\text { c } \\
\text { c } \\
\text { L }\end{array}$ & 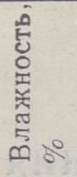 & 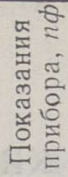 \\
\hline $\begin{array}{l}1 \\
2 \\
3\end{array}$ & $\begin{array}{c}0 \\
14,17 \\
17,87\end{array}$ & $\begin{array}{l}192 \\
312 \\
352\end{array}$ \\
\hline
\end{tabular}
лення минеральной ваты. В табл. 6 приведены результаты измерения смеси сланцевой золы и песка, а их химнческий состав приведен в табл. 5 .

Емкостное сопротивление золы зависит также ог степени гашения ее. Например, золе марки АI-4 со степенью гашения ее в автоклаве до $10 \%$ соответствует показание прибора 78 пф, а негашенной золе - 102 иф. Таким образом, при регулировании смеси используется два таких прибора: один для получения данных о стеґени гашения и другой, принимающий эту ннформацию для регулирования смеси.

Прибор можно также использовать в качестве датчика влагосодержания во фрезерном торфе и других сыпучих материалах. Результаты измерения влагосодержания фрезерного торфа приведены в табл. 7.

Инститит кибернетики

Академии наук Эстонской ССР

\section{Поступила в редакцию} 16. VIII 1963

\title{
MITMEKETTALISTE PÖÖRLEVATE VÓLLIDEGA PIDEVATOIMELINE MAHTUVUSTAJUR
}

\author{
E. Künnap, \\ tehnikateaduste kandidaat
}

Resümee

Paljudes tehnoloogilistes protsessides sõltub produkti kvaliteet lähteainete hulga valuekorra täpsusest. See kehtib ka praegu veel uurimisjärgus oleva energoklinkriseadme kohta, kus lähteaineiks on peenendatud pőlevkivi ning paekivi, produktiks aga klinker ja soojusenergia auru kujul. Joonisel 1 on esitatud tööstusliku katseseadme lihtsustatud skeem, mille kohaselt põlevkivis muutlikul hulgal leiduvale $\mathrm{CaCO}_{3}$-le tuleb paekivi lisada sel määral, et pärast segu põlemist seadme tsüklon- või aerofontaankoldes oleks $\mathrm{CaO}$ hulk klinkris nõutavais piires.

Klinkri lähteainete hulga vahekorra reguleerimiseks valmistati pidevatoimeline mahtuvustajur (joon. 2 ja 3), mille töötamine põhineb kerogeeni ja lubjakivi dielektriliste konstantide erinevusel.

Seda tajurit saab kasutada ka teiste puisteainete hulga määramiseks nende mehaanilisés segus, kui neil on erinevad dielektrilised konstandid. Nii saab tema abil määrata näiteks liiva ja kustutatud tuha hulka mehaanilises segus, mida kasutatakse mineraalvati valmistamiseks. Samuti on temaga võimalik mõõta mitmesuguste ainete (näit. freeslurba) niiskuse muutumist.

Eesti NSV Teaduste Akadeemia Küberneetika Instituut
Saabus toimetusse

16. VIII 1963

\section{CONTINUOUSLY ACTING CAPACITOR TRANSDUCER WITH MULTIDISK ROTATING SHAFTS}

\section{E. Künnap}

\section{Summary}

In several technological processes the quality of the output depends on the accuracy of the dose of the initial strew material.

In this particular case this problem concerns the regulation of the technological process of the energy-clinker equipment where the initial materials are oil shale and limestone, and the output is clinker and steam as thermal energy carriers.

In the initial material the amount of calcium carbonate must be regulated in the way that after combustion in fountain or cyclone furnaces the amount of calcium oxygen is within a fixed limit.

For this purpose a continuously acting capacitor transducer has been made, based on the difference of the dielectric constant of organic substance in oil shale and limestone.

The apparatus may also be used to measure the water content in strew materials.

\section{Academy of Sciences of the Estonian S.S.R.,} Institute of Cybernetics

Received 